\title{
Escuela Secundaria Obligatoria. Los docentes frente al desafío de construir nuevas formas de disciplinamiento
}

\author{
Noelia Andrea Orienti \\ (Universidad Nacional de La Pampa. Argentina)
}

\section{Resumen}

La recientemente sancionada Ley de Educación Nacional interpela los sentidos del proyecto fundacional del nivel secundario, ligados a la educación de un grupo selecto, al establecer la contención de todos/as y quitar a las escuelas la facultad de elegir quiénes permanecen. Este artículo pretende analizar algunos de los desafíos -en clave de disciplinamiento- que suscita en las prácticas docentes la instauración de la obligatoriedad hasta el último año de la escuela secundaria, al impedir que los problemas que se presentan en la cotidianeidad se resuelvan por la vía de la sanción que lleva a la expulsión. Atendiendo al hecho de que la escuela no es un puerto de llegada de innovaciones sino un lugar de constante negociación entre lo impuesto y lo practicado, se insiste en la urgencia de revisar la concepción de los límites que sustentan los profesores, vinculada a la obediencia y la imposición. Se trata de una propuesta para reflexionar desde nuestro lugar de adulto-docente en torno a algunos debates tendientes a construir otras formas de disciplinamiento que se adapten a los nuevos escenarios, den respuesta a las demandas de alumnos reales e inciten a la participación como modelo de organizar y regular la vida cotidiana.

\section{Palabras clave}

Escuela Secundaria - Obligatoriedad - Nuevas Formas de Disciplina - Docentes Límites.

\section{Summary}

The recently sanctioned National Education Law questions the purposes of the initial foundation of the High School academic system, based upon the education of a select group, establishing that all students have to continue and removing the schools' ability to choose which students remain enrolled. This article attempts to analyze some of the disciplinary challenges that evoke the establishment of obligation in educational practices through the last year of High School to prevent the day-to-day problems 
which presents themselves from being resolved through disciplinary actions that result in expulsion. Paying attention to the fact that high schools are not entry ports for new ideas rather places of constant negotiation between what is imposed and what is practiced, is insisted urgency upon to revise the understanding and definition of the boundaries which support the teachers, connected to obedience and imposition. This paper deals with a proposal to reflect, from our place of adult/teacher, on some debates aimed at constructing other forms of discipline that adapt to modern settings, giving an answer to real students' demands and inciting participation as a model to organize and regulate everyday life.

\section{Key words:}

High School - School Obligation - New Discipline Forms - Teachers - Limits.

\section{Introducción}

Transitamos por un momento histórico de generalizada incertidumbre, originada por cambios vertiginosos que configuran desconcertantes contextos educativos. En el marco de profundas transformaciones socio-culturales, de crisis de la cultura escolar, debilitamiento de la autoridad docente, donde los adolescentes y jóvenes cuestionan la validez de la escuela como instrumento de socialización y de producción de sentido (Urresti, 2000), nuevas y diversas demandas pujan por modificar los significados del proyecto fundacional de la escuela secundaria y afectar los viejos modos de hacer las cosas en las instituciones. Sin embargo, las huellas del proyecto Moderno permanecen instaladas en las prácticas, legitimando un orden disciplinario arbitrario y homogeneizante.

Este artículo recupera de los registros de la cotidianeidad escolar una preocupación que desde hace algunos años se ha vuelto constante en el discurso de directores, preceptores y profesores: la dificultad de convivir en la escuela con Otros, que se expresa como la imposibilidad (al menos aparente) de establecer normas, sentidos comunes que habiliten diálogos intergeneracionales, interculturales y se traduzcan en contextos propicios para enseñar y aprender. En la búsqueda de respuestas a esta problemática nos proponemos reflexionar aquí sobre los desafíos que la extensión de la obligatoriedad escolar -que prescribe la reciente Ley de Educación Nacional (1)- suscita en las prácticas institucionales y áulicas del nivel secundario.

En términos cuantitativos, la masificación y universalización del nivel representa un enorme desafío (más escuelas, equipamientos y docentes). Pero el ingreso a las aulas de alumnos muy diferentes a los que tradicionalmente transitaban la educación secundaria conlleva un reto aún mayor: la necesidad de repensar las instituciones, esto es, despojarlas de todos 
los rasgos heredados de su historia de segregación y concebirlas como instituciones democráticas que partan de un profundo conocimiento (y respeto) de esta nueva generación de adolescentes. Explica Tenti Fanfani (2009) que la obligatoriedad no sólo establece el cambio de sentido, sino también determina una serie de transformaciones en los dispositivos y procesos institucionales. Es así que a partir de la Ley de Educación Nacional, en las escuelas secundarias dispositivos vinculados con las tradicionales funciones del nivel -como por ejemplo las amonestaciones- ya no llevan a la expulsión de los estudiantes. Cabe entonces cuestionarnos: ¿Qué desafíos, en clave de disciplinamiento, produce el mandato de permanencia de todos/as los/as adolescentes en un nivel educativo que históricamente expulsó lo "popular", "diferente", "molesto", "inadaptado"?

Si bien reconocemos que la extensión de la obligatoriedad pone frente a quienes definen los lineamientos del diseño curricular dos de los retos más urgentes del siglo XXI: la problemática de la desigualdad social y el contacto cultural (De Alba, 2007), interesa detenernos en el sujeto "docente" como actor privilegiado de la puesta en marcha de un proyecto político y pedagógico, ya que si bien las prescripciones "diseñan los contornos de lo posible (...) no inhiben que otros repertorios sean activados, construyendo actos no previstos" (Gonçalves Vidal, 2007, p. 3).

Nos cabe el compromiso de aprehender otras formas de constituir el orden desde modos de participación democráticos que permitan trabajar con las diferencias al interior, ya no teniendo como meta la homogeneidad ni la selección de los "más aptos". En este sentido, se torna insoslayable para todos los que nos desempeñamos como docentes del nivel secundario y como formadores de formadores preguntarnos: ¿Cómo construir nuevas formas de disciplinar que se adapten a los imperativos del nuevo escenario contemporáneo y coadyuven al cumplimiento del mandato legal? ¿Qué límites podemos sostener y cuáles tenemos que resignificar para dar respuestas adecuadas a la escolarización de sujetos del Siglo XXI?

\section{El agotamiento del proyecto moderno frente a los cambios epocales}

En un análisis sobre las asimetrías entre la institución escolar y el momento histórico y cultural en el que ésta se inserta, Guillermina Tiramonti (2005) afirma que la escuela parece estar en un lugar de resistencia cultural y no de apertura e intercambio con la cultura contemporánea. Sin embargo, después de una década y media de reformas educativas, el tema sigue siendo una cuestión no resuelta y escasamente ventilada en la esfera de la discusión pública. Ante la ausencia de espacios de debate genuinos, los medios masivos de comunicación construyen una imagen de la escuela 
ligada a discursos catastróficos, que parecen volverse parte del paisaje cotidiano: docentes ridiculizadas en la Web por sus alumnos, colegios tomados por estudiantes, alumnas brutalmente agredidas por sus compañeras a la salida de la escuela, aulas vacías por los conflictos gremiales, bochazos masivos en los ingresos a las Facultades. El abordaje mediático de estas problemáticas se asume desde la concepción simplista que postula que lo que allí sucede es consecuencia de un funcionamiento deficitario de la institución y de los sujetos escolares, que se presentan desvinculados de los procesos que tienen lugar en la sociedad local y global. Por el contrario entendemos que, aunque disímiles, todas esas situaciones revelan que los contextos no son los mismos de otros siglos, cuando la Pedagogía Moderna pudo articular respuestas adecuadas para que la escuela se hiciera cargo de la educación.

En nuestro país la escuela pública ha sido uniforme (2), idea que establece una equivalencia entre igualdad y homogeneización, entendiendo igualdad no como acceso igualitario al goce de derechos políticos, civiles y sociales, sino como igualdad cultural. Por ello es que desde sus orígenes la escuela pretendió un mismo patrón para todos, donde el uso del tiempo y los espacios escolares, la sanción de la impuntualidad, la implementación de uniformes escolares, la supresión de castigos corporales, fueron algunas de las normas codificadas que coadyuvaron para legitimar ese proyecto (Brener y otros, citado en Puiggrós, 1990).

Inés Dussel (2009) afirma que la historia del nivel secundario en nuestro país configuró una suerte de gramática escolar que perduró durante todo el siglo XX y que, aún cuando el cambio histórico modifica el entramado institucional construido por la modernidad, pueden observarse continuidades con estas tradiciones heredadas de la escuela media. Entre los elementos de dicha matriz la autora destaca "la organización centralizada del nivel (...); el currículum humanista enciclopédico como puntal de la jerarquía de saberes que establecía la escuela; la organización de las aulas, rituales y disciplina escolar que seguía formas rígidas, centradas en los adultos y pensadas para la formación de la élite; la estructura de horarios y recreos que perpetuaba la fragmentación del saber y la desarticulación de la propuesta formativa en pequeños gajos. Pero sobre todo, hay un aspecto que define una parte importante de lo que mantenía una identidad de las escuelas secundarias argentinas: durante todo ese tiempo, perduró una sensación de "pertenecer" a un grupo definido y selecto, y esa pertenencia, se creía, permitía acceder a una formación que daba un cierto espíritu e identidad a sus actores, que unificaba a docentes y alumnos en la percepción de estar haciendo algo significativo para sus vidas, y para la del país" (Dussel, op. cit., p. 45). 
De este modo destaca que, más allá del "mito igualitarista", la escuela produjo y produce desigualdades importantes. Actualmente, las cifras alarmantes de abandono y repitencia en el nivel medio expresan que la expansión del nivel secundario no ha traído como consecuencia más egresados. Tal como expresa Flavia Terigi (2008), hoy es impensable que la homogeneidad per se sea productora de justicia. La consideración de este hecho torna imperioso, en el marco de un proyecto democrático, que el par igualdad-homogeneidad se actualice atendiendo a las transformaciones contemporáneas y su impacto en los contextos y sujetos escolares. La cultura de las instituciones escolares seguirá chocando con los sentidos que nuestros alumnos le otorgan a la escolaridad si no atendemos a sus condiciones de vida y a su cultura, impronta de los efectos de la globalización y la posmodernización en curso. Lo cual implica en primer término reconocer cuáles son los cambios epocales que dan paso a nuevas formas de habitar la escuela.

\section{Algunos cambios recientes para comprender a los (nuevos) adolescentes}

Los adolescentes que hoy habitan en las aulas pertenecen a escenarios que son inevitablemente diferentes a los que guardamos en nuestra memoria. Como se expone en el Informe sobre tendencias sociales y educativas en América Latina:

"Los factores que alejan a la escuela de sus clásicos alumnos y ponen en riesgo su capacidad de garantizar una educación de calidad van más allá de los efectos de la masificación, como la mayor diversidad social y cultural de su alumnado. Aún aquellos adolescentes que provienen de los sectores sociales que históricamente accedieron a la educación secundaria, hoy son diferentes (...). Se está configurando una nueva adolescencia, más alejada de la cultura letrada, atravesada por la televisión e Internet, con formas de entretenimiento estructuradas en torno a las nuevas tecnologías y en espacios de socialización que, en muchos casos, se resuelven en el espacio virtual" (IIPE-UNESCOOEI, 2008, p. 116).

Estos "nuevos" adolescentes nacieron en escenarios atravesados por nuevas dinámicas, que incluyen al conjunto de la sociedad. En este sentido, es importante destacar que desde hace décadas complejas transformaciones en el plano de lo social, político, cultural y económico impactan en la institucionalidad de la escuela y quiebran la moderna idea de lo común. 
En el plano regional y nacional, se presenta un contexto socio-político de fragilidad de lo público, de deterioro del imperio de la ley y de debilitamiento de la capacidad regulatoria del Estado. La gran transformación acontecida en el espacio público permite hablar de una nueva modernidad que abre paso a una democracia de individuos a secas y no ya de ciudadanos, situación que se relaciona estrechamente con los procesos de desregulación y de privatización de las responsabilidades que fueron originalmente asignadas a los Estados Modernos, y que se ven transformadas ante la irrupción de la globalización, que rompe con la matriz societal al instaurarse con fuerza el mercado como regulador.

La globalización de los mercados, de la mano de las transformaciones tecnológicas, establece nuevas formas en la organización de los procesos productivos que se adapten a una demanda fluctuante. La flexibilidad alcanza también a las formas de organización del trabajo, que exigen otras capacidades para adaptarse a las nuevas relaciones laborales.

En el marco de la transnacionalización del capital y la fuerte interdependencia tecnológica y financiera entre los países, tiene lugar un fuerte proceso de transnacionalización de la cultura, caracterizado entre otras cosas por una formidable concentración de aparatos de producción y difusión de bienes culturales (Gamarnik, 2008). En esta mundialización de la cultura (que permite que sintamos como parte de nuestros hábitos cotidianos hacer las compras en Wall Mart, ir a comer a McDonald's, informarnos con la CNN, ver películas hollywoodenses, por ejemplo), se redefinen las identidades colectivas, la idea de lo popular. Asimismo, la lógica del mercado transnacional convive con el resurgimiento de reivindicaciones locales, nacionalismos, fundamentalismos. Estas tendencias a revitalizar las identidades llevan con frecuencia a nuevas formas de discriminación y exclusión.

La razón económica imperante repercute en el ámbito social, acentuando desigualdades económicas y sociales, y generando grandes movimientos migratorios que dan por resultado sociedades multiculturales. Las fronteras territoriales se desvanecen, y al interior de los diferentes territorios que se conforman las diferencias no siempre son respetadas, ni gozan de políticas justas y equitativas.

Los medios masivos de comunicación alimentan estos circuitos diferenciales, incentivando el consumo y marcando territorios de distinción y exclusión social. Los grupos hegemónicos se transforman en actores políticos cuyo campo de acción es el planeta, y en la búsqueda de maximización de ganancias, lo importante es que su consumo se difunda a escala internacional, obteniendo un valor central el marketing y la publicidad, que promueven que las mercaderías se adquieran no ya por su valor de uso, 
sino por la marca, la distinción (Gamarnik, op. cit.). Desde las posibilidades de acceso a la educación y al disfrute de ciertos productos artísticos, a las posibilidades de una alimentación adecuada, a vivir en condiciones habitacionales dignas y disponer de tiempo libre, para mencionar sólo algunos aspectos, el terreno del consumo ha sido terreno de exclusión y distinción social. Si bien la apropiación desigual de los bienes culturales no es un dato nuevo en nuestras sociedades, lo cierto es que Internet vino a crear una nueva brecha: la brecha digital, donde la exclusión económica y social y la exclusión de los circuitos de producción/circulación del conocimiento sobre redes electrónicas tienden a asociarse cada vez más.

Con la revolución digital, se transforman los espacios socio-culturales propios del Siglo XX, afectando de manera irreversible la vida de los países y de las personas. Los cambios tecnológicos implican transformaciones en los estilos de vida, en las prácticas productivas, en los medios de comunicación y transporte, en las formas organizacionales y de pensar teórico cotidiano (De Alba, op. cit.). Las nuevas tecnologías de la información y la comunicación nos ponen frente a desafíos inusitados, más si tenemos en cuenta que los analfabetos (3) en nuevas tecnologías serán los excluidos de la sociedad futura. Pues no hay que perder de vista que estos procesos avanzan de manera desigual y son fuente de tensiones: a la vez que las tecnologías de la información y de la comunicación promueven el crecimiento económico y el desarrollo social de los países "del primer mundo", su expansión se asocia a nuevos procesos de diferenciación, inclusión y exclusión.

En suma, cada vez más, las escuelas secundarias deben interactuar con adolescentes que nacieron y se criaron en un mundo muy diferente a aquél en que nacieron sus padres y sus profesores, y que poco tienen que ver con el modelo de alumno para el que fueron pensadas, o para las cuales sus docentes fuimos formados. De allí la necesidad de que, en la búsqueda de alternativas para los cambios que se requieren en la escuela secundaria (4), no perdamos de vista que la escuela es un artefacto cultural de otra época, que no puede sino encontrar limitaciones extremas cuando insiste en preparar a los jóvenes para el presente y el futuro con los artilugios del pasado.

\section{Entre las huellas de la tradición y la urgencia de responder al paisaje cotidiano}

Las escuelas secundarias constituyen, al decir de Andy Hargreaves (2008), instituciones modernas paradigmáticas, cuyas estructuras y prácticas condensan el sentido de una modernidad que ha perdido su fuerza y 
relevancia. No obstante, las huellas de sus mitos fundantes persisten en el ideario docente y acentúan el enfrentamiento de dos culturas: la de los adolescentes y jóvenes y la que es propia de la tradición escolar. Al respecto, sostiene Tenti Fanfani que "Mientras que el programa escolar tiene todavía las huellas del momento fundacional (homogeneidad, sistematicidad, continuidad, coherencia, orden y secuencia únicos, etc.), las nuevas generaciones son portadoras de culturas diversas, fragmentadas, abiertas, flexibles, móviles, inestables, etc. La experiencia escolar se convierte a menudo en una frontera donde se encuentran y enfrentan diversos universos culturales" (2009, pp. 58-59).

La recientemente sancionada Ley de Educación Nacional, signada por una fuerte política de inclusión, pretende cambios sustantivos en la configuración de una "nueva secundaria". Es así que establece, entre otros cambios y propuestas, la obligatoriedad de la Escuela Secundaria hasta su último año. Sin desconocer que desde hace décadas el acceso masivo de sectores históricamente excluidos al nivel secundario ha ido acompañado por un profundo cambio en la configuración social de los nuevos ingresantes (lo cual ha complejizado las demandas y tensionando la oferta de estas instituciones escolares) la escuela secundaria obligatoria es fuente de nuevos conflictos y retos para quienes participamos de la experiencia escolar. Por un lado, supone transformaciones en el currículum prescripto, en términos de selección y distribución de contenidos, pues como explica Inés Dussel desde su inicio "el currículum secundario se definió como un compendio de cultura humanista y enciclopedista (...) las humanidades eran un signo de distinción cultural, pero también implicaban un trabajo sobre los individuos, una definición de sujeto que expresaba jerarquías y disposiciones que requerían de esa clase dirigente" (2006, pp. 11-12). Pero también en el currículum real, del cual los docentes participamos activamente.

Flavia Terigi (2008) comparte la idea de que cambiar el formato del nivel secundario no sólo es necesario, sino también posible, pero advierte que frente a la complejidad que implica transformar la escuela secundaria se requiere atender a los rasgos que pueden obstaculizar las iniciativas de cambio y plantear con claridad las condiciones que deben considerarse, a la vez que analizar las restricciones que el desarrollo histórico del nivel impone a las pretensiones de reformulación (5).

Si atendemos a estas restricciones, la construcción de otro orden disciplinario no es un tema menor ya que uno de los rasgos de la escuela que permanece estable más allá de las propuestas de reforma es el disciplinamiento, a través de sanciones (Gonçalves Vidal, 2007). Y entendemos que la prescripción de obligatoriedad lleva implícita la necesidad de cambios 
importantes en materia de disciplinamiento, al imponer la presencia de todos/ as en un nivel cuyo objetivo originario fue "formar a las capas dirigentes con una perspectiva "nacional", es decir, centralista" (Dussel, 2006, p. 11).

Ahora bien, es claro que esto requiere modificaciones en los esquemas de pensamiento, y que éstos no devienen por la simple sanción de una ley. Más allá de la prescripción, habremos de tomar consciencia del agotamiento de un modelo de escuela ligado a la producción de desigualdades (Dussel, 2009) y de la urgencia de ensayar otros modos de enfrentarnos y encontrarnos con diferentes universos culturales para educar a sujetos contemporáneos. En este sentido, pretender que los estudiantes de hoy aprehendan normas de otros tiempos porque "daba buenos resultados" puede convertirse en una tarea frustrante, cuando no con efectos contrarios a los esperados.

En el contexto actual, no es desatinado sostener que idear nuevas formas de convivir dentro de la escuela se vincula con la formación de una ciudadanía democrática, opuestas a un modelo homogeneizante, modelador de cuerpos dóciles, cuyo poder disciplinario califica, clasifica y castiga (Foucault, 1986). La reciente normativa es un paso importante en esta dirección. Pero si la escuela no sólo es el lugar de la inercia y de la rutina, menos aún lo es de la reproducción de mecanismos externos a ella. Coincidimos con el aporte de Gonçalves Vidal (2007) de que las instituciones no son un puerto de llegada de innovaciones pedagógicas y normas legales o reformas sino un lugar de constante negociación entre lo impuesto y lo practicado. En efecto, si reconocemos que no todas las reformas han supuesto cambios -o al menos los cambios esperados- hallaremos que la escuela es un lugar de organización y producción de una cultura propia, donde profesores y alumnos traducimos las reglas en haceres, modificamos normas que consideramos inadecuadas y seleccionamos unos dispositivos en detrimento de otros, en una verdadera elección y reconversión de aquello que nos es propuesto.

Entonces cabe cuestionarnos sobre la responsabilidad que los docentes tenemos en el sostenimiento de ciertas tradiciones que se nos muestran a todas luces inadecuadas, y a las cuales tendemos a volver una y otra vez. Como afirma Tenti Fanfani, "una política efectiva necesita desplegarse en programas e intervenciones específicas cuya construcción excede las capacidades de los expertos y requiere de la movilización de los saberes y voluntades de los principales protagonistas del hecho educativo, es decir, los docentes" (2009, p. 69). En este sentido, los actuales procesos de reforma de los Acuerdos Institucionales de Convivencia (se abordan con mayor detalle en el apartado siguiente), la sustitución de las amonesta- 
ciones por otros modos de proceder frente a la transgresión, entre otras disposiciones relacionadas con la confianza en la escuela como espacio para la consolidación de una ciudadanía democrática, pueden no arrojar resultados alentadores si nos mantenemos en la postura de ser dueños de una razón cuya lógica está en completo desuso para los adolescentes y jóvenes actuales.

Es importante destacar que el citado autor reconoce que, en el marco de una crisis generalizada de las instituciones, la escuela se ha convertido en una institución sobredemandada y subdotada, a la cual más se le exige y menos se le da en términos de recursos de todo tipo. Pero no podemos dejar de considerar que, al interior de las instituciones, quienes traducimos las normativas en acciones concretas, tenemos un compromiso ineludible (6): diseñar situaciones de enseñanza y aprendizaje que atiendan tanto a los condicionantes macro como a las circunstancias de los estudiantes y del contexto más próximo. Si la adaptación de las instituciones y los esquemas de pensamiento no son consecuencia instantánea de las transformaciones estructurales y legales, el análisis de nuestras propias prácticas se vuelve fundamental; pues en el reconocimiento de la adversidad es donde se pueden hallar intersticios que den lugar a oportunidades inéditas. Claro que no resulta una tarea sencilla en tiempos donde los docentes somos interpelados por diferentes actores sociales, nos sentimos desautorizados, a veces estamos paralizados y otras (las más) buscando tiempos y espacios para ensayar respuestas a problemas diversos y urgentes que habitualmente se dirimen en una soledad que se presenta insoslayable.

\section{El reto de la permanencia desde la mirada del adulto-docente}

Como venimos sosteniendo, las escuelas secundarias están transitando el difícil camino que las lleva de ser instituciones que históricamente seleccionaron jóvenes, encaminándolos en trayectorias de vida diferenciadas que profundizaban sus desigualdades sociales de origen, a ser instituciones comprometidas con la integración de las nuevas generaciones y la igualdad en los logros educativos de todos, independientemente de su origen. De este modo, los recursos que fueron constitutivos de la dinámica de este nivel de enseñanza como modos de garantizar excelencia, entre los que se encuentra la posibilidad de expulsión, deja de ser legítimo cuando el espíritu de estas instituciones es precisamente la inclusión de todos/as.

De allí que en los últimos años las instituciones comenzaran a revisar sus regímenes disciplinarios, constituyendo lo que se denomina Acuerdo Institucional de Convivencia. Como observan Litichever y otros al realizar una investigación reciente sobre el tema: 
"En general, se trata de lograr una transición desde formas disciplinarias centradas en una autoridad burocrático-legal, ligadas al empleo de las amonestaciones, suspensiones y firmas de actas, a otras formas reflexivas e individualizadas, fundadas en acuerdos, contratos o negociaciones establecidas entre los diferentes miembros de la comunidad educativa. Los reglamentos de convivencia se plantean como instrumentos que permiten mejorar la convivencia y generar mayores vínculos entre jóvenes y adultos, así como también transcender el carácter punitivo de la sanción prevista, a fin de lograr la reparación de la falta cometida frente a la transgresión de la norma" (2008, p. 95).

Estos autores exponen que aún cuando la mayoría de las instituciones cuentan con Reglamentos de Convivencia, en muchos casos las nuevas prácticas no fueron internalizadas por toda la comunidad ni parecen concebirse como una manera pertinente para resolver las situaciones a las que se enfrentan.

Sucede que los límites son una construcción colectiva y representa un gran desafío hacer de las normas un instrumento a favor de la convivencia y del trabajo que atienda a los nuevos imperativos de la época, cuando la escuela durante siglos se encargó de naturalizar la homogeneidad, y establecer que quienes persistan en afirmar su diversidad sean percibidos como un peligro para esa identidad colectiva, o como sujetos inferiores. En este sentido, Inés Dussel advierte que "hoy cuando se escuchan clamores por volver a la "vieja y gloriosa secundaria", sería bueno recordar que el currículum humanista tradicional se estableció sobre la base de muchas exclusiones, y que reprodujeron por mucho tiempo una jerarquía cultural que legitimaba desigualdades sociales y regionales muy agudas" (2006, p. 12).

Este anhelo de querer volver a la "vieja y gloriosa secundaria" demuestra líneas de continuidad con las tradiciones heredadas del nivel. Como señala Dussel, la idea de "educar para la distinción y la jerarquía social se mantuvo presente, aún cuando las aulas se poblaron de alumnos que no pertenecían ya a la élite, y cuando las formas de distinguirse y relacionarse habían cambiado profundamente" (2009, p. 46). En la misma dirección Nicolazzo, en una investigación reciente sobre las transformaciones de la identidad de los profesores de secundaria en la provincia de Buenos Aires, señala una sensación de melancolía por la identidad perdida: "Los profesores se sienten demasiado lejos de sus alumnos, como habitantes de mundos opuestos: otros códigos culturales, otras expectativas, otras formas de entender el mundo y la vida" (2005, p. 123, citado en Dussel, 2009). 
Los adultos fuimos parte de otro modelo y tenemos internalizada una concepción de las normas, los límites, ligada a la obediencia, la imposición y la sumisión. Tal vez de allí proceda la intolerancia (cuando no el pavor) ante la diversidad de modos de habitar la escuela que ensayan los adolescentes.

En efecto, si hacemos foco en lo que sucede en el día a día escolar, se vuelve visible cierto malestar que hace eco en los pasillos, el despacho del Director y la sala de profesores: los chicos de hoy "no tienen límites", "no reconocen autoridad" alguna. Por momentos parece no existir otra posibilidad que "no darle bolilla y que se lleve todas las materias de nuevo así se cambia de escuela" o bien llamar a sus padres todas las semanas para que vengan a firmar actas de acuerdo. El desorden se vive como una situación de constante desborde y, ante la ausencia de acuerdos institucionales sólidos y/o participativos, cada cual resuelve las situaciones desde sus propias representaciones y con diversidad (cuando no polaridad) de estrategias. Así, por ejemplo, frente a los docentes que se muestran intransigentes ante la desobediencia de estos "fenómenos" contemporáneos (pibes chorros, floggers, madres precoces, emos, darks, rollingas, adictos al paco y tantos otros... jestudiantes!) están los "profes" que celebran cierta rebeldía en los chicos, y negocian un poco de silencio durante el teórico, la fecha de entrega de trabajos prácticos o más contenidos en las evaluaciones a cambio de quince minutos de recreo, escuchar música con el $\mathrm{mp} 3 \mathrm{o}$ exámenes "a carpeta abierta".

Los incidentes que se producen en el paso de las horas de un profesor a otro son bien conocidos. Detener la mirada en las controversias diarias originadas por la "falta de límites" de los chicos, nos muestra que el sentido de los límites que solíamos respetar a raja tabla ha caducado. En análisis sobre estas situaciones duales nos llevan a preguntarnos si las dificultades de los alumnos para acatar las normas no se deben en parte a las dificultades que tenemos los adultos para hacer comprensibles y creíbles nuestros mensajes. Si esto es así, si los adultos no estamos siendo claros y convincentes en lo que proponemos, se plantea la necesidad del debate en las escuelas sobre el establecimiento de normas consensuadas y explícitas para convivir fuera y dentro de la misma, para lo cual habremos de habilitar la palabra de los chicos también.

Habilitar diálogos intergeneracionales, concebir a los alumnos como transformadores y constructores de cultura, como sujetos de derecho, es desterrar de una vez y para siempre la idea de los adolescentes de hoy como portadores de violencia. Resultan esclarecedoras al respecto las ideas expuestas en el Informe sobre tendencias sociales y educativas en América Latina: 
"El riesgo es que, como respuesta a la violencia que puedan acercar los alumnos a las aulas, se desarrollen nuevas formas de violencia institucional desde los propios establecimientos educativos. Es visible el esfuerzo que realizan muchas escuelas por neutralizar la creciente -y, para ellas, inmanejable- diversidad de su alumnado, mediante mecanismos encubiertos de selección o a través de señales que invitan a que éstos terminen adquiriendo un comportamiento y una identidad que no les es propia. Tales mecanismos suelen ser vividos por los alumnos como expresión de una incapacidad de las escuelas de interactuar con ellos y, consecuentemente, como una solución violenta ante la imposibilidad de un diálogo constructivo" (IIPE-UNESCO-OEI, 2008, p. 140).

Porque la escuela es escenario de encuentro y desencuentro entre generaciones, el compromiso de transmitir conocimientos y generar lazos sociales no nos atañe sólo como docentes sino también como adultos. Nos cabe entonces la responsabilidad de crear nuevos modos de ordenar la vida institucional acordes a las exigencias del contexto, las prescripciones de la Ley, pero también (y en primer lugar) anteponiendo la vulnerabilidad de nuestros alumnos (Zelmanovich, 2003). Si nos corremos del adulto que vigila, controla, sanciona y corrige, podremos platearnos: ¿cómo justificamos hoy el "sacate la gorra adentro del aula", "parate cuando entre la Directora", "hacé esto o aquello porque yo te lo digo"? ¿Quiénes son los "indisciplinados" hoy: los que filman peleas con sus teléfonos celulares, los que concurren con armas o drogas, los que se besan tímidamente en el patio de la escuela, o los que desafían a los profesores a la voz de "iyo hago lo que tengo ganas!"? Aunque las preguntas nos resulten abrumadoras, no podemos atrincherarnos en el deseo de un pasado que, a la luz de los aportes realizados, no siempre ha sido "mejor" ni brinda oportunidades de un aprendizaje genuino.

\section{Una última reflexión: Enseñar es también limitar}

Para algunos profesores la transmisión de límites conlleva un esfuerzo, un desgaste extra, que tiene que ser afrontado por la familia y no por la escuela. No son pocos los que vivencian "los límites" como una tarea paralela a su tarea específica: la enseñanza. Se trata de una representación de los límites asociada de manera casi exclusiva a la disciplina, a las normas de convivencia, que se presenta en disyunción con la enseñanza, o en todo caso, como un plus (Kiel, 2005). Usualmente es una dificultad que se presenta bajo el interrogante: “¿cómo encontrar tiempos para enseñar si me paso la hora tratando de ordenarlos?”. 
Entendemos que quizá desde nuestro lugar la clave para construir nuevas formas de disciplinamiento esté en ligar la enseñanza curricular con la trasmisión de límites, es decir limitar para justificar los "para que sí "(podamos comprendernos, descubrir, inventar, conocer, imaginar...) en vez de los “iporque no!". En el proceso de construir nuevas formas de disciplinamiento que garanticen la convivencia en democracia y el aprendizaje de todos/as, se hará necesario discutir no sólo lo que los límites prohíben sino también lo que permiten; preguntarnos cuáles se pueden sostener hoy y cuáles tienen que ser resignificados, de acuerdo a lo que posibilitan, y no sólo a lo que limitan y vedan (Kiel, op. cit.).

Aprender implica la internalización de ciertos límites, y es en este sentido que decimos que enseñar es limitar. Ligar la enseñanza con los límites requiere idear caminos para "reforzar aquellos límites que se encuentran en el acto mismo de la enseñanza y que dan la oportunidad de jugar un deporte reglado, de tocar un instrumento, de encontrar sus raíces en una clase de historia o de descubrir algo por lo que valga la pena hacer el esfuerzo de estudiar" (Kiel, op. cit., p. 9). Exige también experimentar nuevas formas de autoridad, ligadas a una profunda reforma de la "formación intelectual y moral" y de las condiciones de trabajo de los docentes (Tenti Fanfani, 2009). Como mediadores entre las nuevas generaciones y la cultura, nos cabe encontrar la sabiduría necesaria para motivar, movilizar, interesar y hasta para cautivar y seducir a los alumnos.

La educación pública en nuestro país se inscribe en un contexto de pobreza material y simbólica y, a diferencia de otras épocas, las expectativas que genera el sistema educativo en términos de autorrealización y movilidad social, chocan con los mecanismos de selección y exclusión del propio sistema escolar y del mercado laboral. Por esto, acaso más que nunca, no revisar las propias miradas sobre los adolescentes y sus circunstancias, puede promover prácticas tendientes a trasladar los mecanismos de exclusión al interior de la escuela. Debemos acabar con la inercia que suscita considerar siquiera la posibilidad de que "los jóvenes de hoy están perdidos" o la desidia de postergar su educación "porque ya tienen demasiados dramas en sus vidas, ipobres!".

El proceso de construcción de nuevos órdenes disciplinarios requiere reflexionar sobre los modos en que resignificamos la obligatoriedad en el nivel secundario que prescribe la nueva Ley. La escuela secundaria obligatoria nos interpela para afianzar el compromiso con la educación de todos/as. No ignoramos el hecho de que garantizar el acceso no es igual a garantizar la permanencia, y permanecer no significa aquí convertir a la escuela en un espacio de aguante o control del riesgo social (Tiramonti, 
2005), un lugar de la no-norma, sino "instalar a los jóvenes como herederos, como deudores, como un eslabón en esta cadena que nos constituye como sujetos" (Kiel, op. cit., p. 11).

En la tentativa de bosquejar respuestas, insistimos en "el riesgo de quedar atrapados en un círculo vicioso, de manera que cuanto más muestren los viejos límites su debilidad para regular la convivencia, más tendamos a aferrarnos a los mismos" (Kiel, op. cit., p. 2). Quizá encontremos una clave importante para impulsar los cambios que tenemos por delante en "la fuerza de la imaginación", condición sine qua non en la constitución de nuevo tejido social, de nuevos sujetos sociales y educativos (De Alba, 2007).

\section{Notas Bibliográficas}

(1) La Ley de Educación Nacional № 26.206 aprobada por el Congreso de la Nación Argentina en diciembre de 2006, establece en su artículo 16 que la obligatoriedad escolar en todo el país se extiende hasta la finalización del nivel de la Educación Secundaria inclusive. En el caso de la provincia de Buenos Aires, tras la sanción de la Ley № 13.688, el Nivel Secundario es obligatorio, de seis años de duración y se organiza como una unidad pedagógica básica, conformada por dos ciclos de tres años cada uno. El primero está comprendido por una formación de carácter común (Secundaria Básica, ex Tercer Ciclo) y el segundo es orientado, de carácter diversificado, respondiendo a diferentes áreas del conocimiento, del mundo social y del trabajo (Secundaria Superior, ex Polimodal). La nueva secundaria busca formar para adquirir saberes y continuar los estudios; fortalecer la formación de sujetos de derecho con capacidad de ejercer y construir ciudadanía, y vincular la escuela con el mundo del trabajo.

(2) El Sistema Educativo Argentino se fundó -tras la sanción de la Ley de Educación Común en 1.884- en el contexto de la construcción del Estado-Nación, con el objetivo político de propagar la idea de supremacía de la identidad nacional.

(3) Se entiende por este nuevo tipo de analfabeto al ciudadano que no es capaz de acceder a la información, pero también aquél que no sabe seleccionarla, que no la comprende o que no sabe interpretarla críticamente (Casas Vilalta, 2003, p. 4).

(4) Coincidimos con la perspectiva de Flavia Terigi (2008), de que dichos cambios tendrían que apuntar a incrementar las posibilidades de inclusión de nuevos públicos y a mejorar la relevancia cultural y social del nivel para todos las y los jóvenes.

(5) En este sentido, Terigi explica que en la educación secundaria argentina "la clasificación de los currículos, el principio de designación de los profesores por especialidad y la organización del trabajo docente por horas de clase se enlazaron entre sí de tal modo que hoy conforman un trípode de hierro, un 
patrón organizacional que está en la base de buena parte de las críticas del nivel y que es difícil de modificar" (2008, p. 64).

(6) Tal vez sea preciso advertir que no estamos postulando aquí que "la responsabilidad" es de los docentes. Por supuesto que hay condicionamientos muy fuertes en los que no tenemos injerencia y que la posibilidad de que la obligatoriedad sea una realidad y no sólo la declaración de una ley, requiere de voluntad política. Vale decir, que el Estado se haga cargo de garantizarla a través de un conjunto de políticas educativas y sociales, tales como: construcción y equipamiento de escuelas, formación de los profesores, ampliación de becas y otras medidas socioeducativas que permitan sostener la escolarización de los adolescentes y jóvenes en todo el terreno nacional.

\section{Referencias Bibliográficas}

- $\quad$ Argentina. Ley 26.206. Ley de Educación Nacional. Buenos Aires. Ediciones Ocampo SRL.

- Casas Vilalta, M. Algunas reflexiones sobre la formación para la ciudadanía democrática. Pensar en el futuro partiendo del presente. En: www. cervantesvirtual.com/servlet/SirveObras/.

- De Alba, A. (2007) Curriculum - sociedad. El peso de la incertidumbre, la fuerza de la imaginación. México, IISUE-UNAM, Plaza y Valdés.

- Dussel, I. (2006) El curriculum: aproximaciones para definir: Qué debe enseñar la escuela hoy. Versión preliminar. Buenos Aires, Mimeo, FLACSO.

- Dussel, I. (2009) "La escuela media y la producción de la desigualdad: continuidades y rupturas", en Tiramonti, G. y Montes, N. (comp.) La escuela media en debate. Problemas actuales y perspectivas desde la investigación. Buenos Aires, Manantial-FLACSO.

- Foucault, M. (1986) “Los cuerpos dóciles", en Vigilar y castigar. Madrid, Siglo XXI.

- Gamarnik, C. (2008) La cultura masiva, la cultura mediática y la escuela: vínculos, cruces y posibilidades, en Diploma Superior en Curriculum y Prácticas Escolares en Contexto-Cohorte 13, FLACSO-Argentina.

- Gonçalves Vidal, D. (2007) "Culturas escolares: entre la regulación y el cambio", en Revista Propuesta Educativa $\mathrm{N}^{\circ} 28$. Buenos Aires, FLACSO.

- Hargreaves, A. (2007) "El cambio educativo: entre la seguridad y la comunidad", en Revista Propuesta Educativa № 27. Buenos Aires, FLACSO, pp. 63-69.

- IIPE-UNESCO y OEI. La escuela y los adolescentes. Informe sobre tendencias sociales y educativas en América Latina 2008. Buenos Aires.

- Kiel, L. (2005) "De sin límite a limitados", en Materiales para la Capacitación. Escuela de Capacitación CePA (Centro de Pedagogías de Anticipación), Secretaría de Educación, Ciudad de Buenos Aires.

- $\quad$ Litichever, L., Machado, L., Núñez, P; Roldán, S. y Stagno, L. (2008) “Nuevas y Viejas Regulaciones: Un análisis de los reglamentos de convivencia en la 
Escuela Media", en Revista Última Década № 28, Valparaíso, CIDPA, pp. 93-121.

- Puiggrós, A. (1990) Sujetos, disciplina y curriculum. Buenos Aires, Galerna.

- Tenti Fanfani, E. (2004) "Viejas y nuevas formas de autoridad docente", en Revista Todavía, S/D.

- Tenti Fanfani, E. (2009) "La enseñanza media hoy: masificación con exclusión social y cultural", en Tiramonti, G. y Montes, N. (comp.) La escuela media en debate. Problemas actuales y perspectivas desde la investigación. Buenos Aires, Manantial- FLACSO.

- Terigi, F. (2008) "Los cambios en el formato de la escuela secundaria argentina: por qué son necesarios, por qué son tan difíciles", en Propuesta Educativa $\mathrm{N}^{\circ} 29$, pp. 63-72.

- Tiramonti, G. (2005) "La escuela en la encrucijada del cambio epocal", en Educação e Sociedade, vol. 26, n 92, pp. 889-910.

- Urresti, M. (2000) "Cambio de escenarios sociales. Experiencia juvenil urbana y escuela", en Tenti Fanfani (Comp.) Una Escuela para los Adolescentes. Buenos Aires, Losada.

- Zelmanovich, P. (2003) "Contra el desamparo", en Enseñar Hoy. Una introducción a la Educación en tiempos de crisis. Buenos Aires, Fondo de Cultura Económica. 